\title{
MUJERES EXTRANJERAS EN PRISIONES ESPAÑOLAS El caso andaluz
}

\section{FOREIGN WOMEN IN SPANISH PRISONS}

The Situation in Andalusia

\author{
Joaquina Castillo Algarra \\ Universidad de Huelva. España \\ Joaquina@uhu.es \\ Marta Ruiz García \\ Universidad de Huelva. España \\ marta@uhu.es
}

\section{Resumen}

El sistema penal español viene experimentando profundos cambios desde los años ochenta. Importantes aspectos de este proceso han sido, por un lado, el notable incremento de la población reclusa femenina -España tiene el mayor número de mujeres reclusas de Europa- y por otro, la presencia de extranjeros en las prisiones españolas, siendo significativo el progresivo aumento de mujeres extranjeras de distintas nacionalidades. Este artículo muestra el perfil sociológico de las mujeres presas en España y, específicamente, en Andalucía; establece su perfil delictivo y analiza la vida en prisión desde las perspectivas de género y extranjería. El trabajo de campo se ha centrado en las prisiones andaluzas de Huelva, Algeciras (Cádiz) y Alhaurín de la Torre (Málaga), empleando la entrevista en profundidad como técnica de investigación principal, que se ha realizado en el interior de los módulos de mujeres.

\section{Palabras Clave}

Delincuencia femenina, Nacionalidad, Reclusas inmigrantes, Sistema penitenciario español.

\section{Abstract}

The Spanish penal system has undergone deep changes since the 1980's. Important aspects of this process have been both the notable increase in the female prison population - Spain now has the highest number of female prisoners in Europe - and the presence of foreigners, highlighting the progressive increase in women immigrants from a variety of countries. This paper shows the sociological profile of imprisoned women for Spain in general, and Andalusia in particular; establishes their criminal profile, and analyses prison life from a perspective which recognises the specificity of gender and nationality. We have centred our field work on the prisons of Huelva, Algeciras (Cádiz) and Alhaurín de la Torre (Málaga). We carried out in-depth interviews with professionals and foreign female inmates. With this in mind, we highlight the relevance of the field work carried out, held inside the prisons, in women's units. 


\section{KEYWORDS}

Female Crime, Immigrant Inmates, Nacionality, Spanish Penitentiary System.

\section{INTRODUCCIÓN ${ }^{1}$}

\section{Mujeres extranjeras en el mapa penitenciario español}

El estudio sobre mujeres extranjeras en prisión requiere la incorporación de nuevas perspectivas en los estudios sobre prisiones que tengan en cuenta las variables de género y extranjería. El ámbito penitenciario es, además, una institución de carácter total, en la que la problemática de las mujeres internas -en particular las extranjeras- presenta unas peculiaridades y una intensidad mayores que en los reclusos varones.

En la actualidad, el 37,53\% de la población penitenciaria en España es extranjera, lo que implica que uno de cada tres reclusos presenta una nacionalidad distinta de la española (Tabla 1). Esta evolución de los reclusos extranjeros en nuestro país ha sido puesta de manifiesto por distintos autores (Miranda 1997; Surt, Sacro, CGIL y Faire 1999; García España 2001; Ribas, Almeda y Bodelón 2002; Díez Ripollés 2006).

Tabla 1.

Reclusos españoles y extranjeros en España, por sexo.

\begin{tabular}{lcccccc}
\hline AÑO 2007 & HOMBRES & $\%$ & MUJERES & $\%$ & TOTAL & $\%$ \\
\hline ESPAÑOLES & 40.462 & 6,0 & 3.516 & 67,1 & 43.978 & 67,9 \\
EXTRANJEROS & 19.015 & 31,9 & 1.717 & 32,8 & 20.732 & 32,0 \\
TOTAL & 59.477 & 100 & 5.233 & 100 & 64.710 & 100 \\
\hline
\end{tabular}

Fuente: Elaboración propia a partir de los Informes de la Dirección General de Instituciones Penitenciarias, de los Anuarios Estadísticos 2004 y 2005 del Ministerio del Interior y de la página web de Instituciones Penitenciarias (www.mir.es).

En lo que respecta a las mujeres reclusas, el crecimiento de las extranjeras ha sido mayor que el de las internas españolas, quienes en 1999 representaban más del 81\% del total las mujeres reclusas, disminuyendo al $61,1 \%$ en 2007 (Tabla 1); y también

${ }^{1}$ El trabajo que presentamos se inició en el año 2004, en el marco del Proyecto "Itinerarios de inserción social y laboral de la población inmigrante en Huelva". Referencia SEC 2002-04795, financiado por el Ministerio de Ciencia y Tecnología y los Fondos FEDER. 
mayor que el de los varones extranjeros (las mujeres extranjeras han aumentado más del triple, mientras que los hombres extranjeros no han llegado a triplicarse). Al mismo tiempo, han ido incorporándose nuevas nacionalidades a las prisiones españolas. La siguiente tabla refleja la evolución de las diez nacionalidades más representativas entre las reclusas extranjeras entre 2003 y 2005.

Tabla 2.

Reclusas extranjeras en España, por nacionalidad.

\begin{tabular}{lrr}
\hline NACIONALIDAD & & MUJERES \\
\hline COLOMBIA & $\mathbf{2 0 0 3}$ & $\mathbf{2 0 0 5}$ \\
RUMANÍA & 346 & 347 \\
BRASIL & 64 & 115 \\
MARRUECOS & 81 & 105 \\
VENEZUELA & 69 & 97 \\
REP. DOMINICANA & 48 & 69 \\
NIGERIA & 16 & 49 \\
ECUADOR & 24 & 47 \\
BOLIVIA & 42 & 40 \\
FRANCIA & 23 & 33 \\
\hline
\end{tabular}

Fuente: Elaboración propia a partir del Informe General 2003, de la Dirección General de Instituciones Penitenciarias, y del Informe Especial al Parlamento del Defensor del Pueblo Andaluz: Mujeres privadas de libertad en centros penitenciarios de Andalucía 2006.

La nacionalidad con mayor representación es la colombiana. Colombia aparece igualmente como el principal país emisor de mujeres a España (Instituto Nacional de Estadística 2006). La segunda nacionalidad más representada es la rumana; respecto de esta nacionalidad hay que destacar que, a pesar de ser una nacionalidad relativamente reciente en la emigración a nuestro país, el número de internas rumanas se ha duplicado. También destaca el número de reclusas dominicanas en las prisiones españolas, que se triplicó entre 2003 y 2005.

Respecto a la nacionalidad ecuatoriana, llama la atención por ser la única en la que el número de mujeres presas no ha aumentado, hecho muy significativo porque rompe la tendencia creciente de mujeres extranjeras en prisión, vigente para el resto de las nacionalidades. Una explicación a este hecho la podemos encontrar en el carácter familiar de la emigración ecuatoriana, muy asentada en España, y en la que la familia ocupa un papel central, como red de apoyo, proporcionando seguridad y estabilidad a sus miembros. 
Por último, destaca la escasísima presencia de mujeres chinas en las prisiones españolas —dos en 2003 (Informe General 2003: 17-18)² - a pesar de que el colectivo de origen chino constituye la décima nacionalidad más numerosa en nuestro país (INE 2006).

\section{Mujeres extranjeras en las prisiones andaluzas}

Andalucía es la comunidad autónoma con mayor número de reclusos, con aproximadamente el $21,5 \%$ de la población penitenciaria nacional. Sin embargo, en cuanto a la presencia de mujeres reclusas, es Madrid la que tiene la mayor concentración, con el $23 \%$ del total de la población penitenciaria femenina de España; seguida de Andalucía, con un $21,39 \%$, y en tercer lugar, por Cataluña, con un 12,2\%. Del número del total de personas presas en Andalucía, el $91,60 \%$ corresponde a hombres, mientras que las mujeres representan el $8,40 \%$ del total, casi un punto por encima de esta misma relación porcentual a escala nacional. Por otra parte, las mujeres encarceladas en Andalucia suponen el 22,87\% del total nacional (www.mir.es).

En cuanto a nacionalidades, se aprecia un número significativo de reclusas de origen marroquí en todas las prisiones andaluzas, siendo esta nacionalidad la más representada entre la población penitenciaria femenina en Andalucía, en torno al $25 \%$ del total, lo que la convierte en la comunidad autónoma con mayor número de mujeres internas marroquíes. El centro penitenciario de Algeciras concentra a más de la mitad de las internas extranjeras de origen marroquí, lo que se explica porque la mayoría de ellas son detenidas en el puerto de Algeciras, procedentes de Marruecos.

La segunda nacionalidad es la colombiana que, en la mitad de los centros penitenciarios andaluces, constituye el colectivo más numeroso. La cifra total de internas extranjeras en prisiones andaluzas, 200 en $2005^{3}$, representa el $18,5 \%$ de las mujeres encarceladas en esta comunidad.

\section{Objetivos y metodología}

Según muestran los datos analizados, la población reclusa extranjera, tanto en España como en la comunidad andaluza, presenta un crecimiento cada vez mayor. Este crecimiento continúa aumentando, como apuntan los últimos datos publicados, que sitúan el número de reclusos extranjeros en el año 2008 en 26.207, de los que 2293 son mujeres (www.mir.es). No obstante, lo relevante de este fenómeno es el aumento de internas

\footnotetext{
${ }^{2}$ El del 2003 es el último Informe General en el que aparecen los datos desagregados por sexo y nacionalidad. En los posteriores de 2004, 2005 y 2006 sólo se distingue por sexo entre nacionales y extranjeros.

${ }^{3}$ Informe Defensor del Pueblo Andaluz 2008: 121.
} 
extranjeras en relación con el de las españolas, tal y como establecimos anteriormente. Ante esta realidad, en este artículo se abordan los objetivos siguientes:

1. Mostrar los rasgos sociológicos de las mujeres encarceladas en España, en general, y en Andalucía, en particular: lugar de origen, edad, nivel de estudios, situación familiar, situación administrativa y laboral, trayectoria y proceso migratorio.

2. Establecer su perfil delictivo: tipo de delito cometido, circunstancias del delito, tratamiento policial, judicial y penal, y condenas.

3. Recoger directamente, y en el mismo contexto de la prisión, los discursos de las mujeres extranjeras encarceladas.

4. Por último, analizar la vida en prisión en general, y desde las perspectivas de género y extranjería, en particular.

Nuestro trabajo contempla el ámbito penitenciario español, centrándose en el estudio de las prisiones andaluzas; el trabajo de campo ha sido realizado en los centros penitenciarios de Huelva, Algeciras (Cádiz), Córdoba y Alhaurín de la Torre (Málaga). El criterio utilizado para la selección de los centros, en un primer momento, fue el número de mujeres reclusas extranjeras; concretamente, el centro penitenciario de Algeciras contaba con 41 en el momento de la selección y el centro penitenciario de Málaga con 44, más del doble que el resto de las prisiones andaluzas (Defensor del Pueblo Andaluz 2006: 66); además, estos centros concentran a un número de internas que duplica el habitual en el resto de los centros penitenciarios tipo ${ }^{4}$ : el centro de Algeciras tiene 213 internas y el de Alhaurín de la Torre 207. En estos momentos hemos ampliado el trabajo de campo al resto de los centros penitenciarios andaluces y a otros de otras comunidades autónomas con alta concentración de reclusas extranjeras ${ }^{5}$.

Hemos utilizado una "pluralidad metodológica" para llevar a cabo la investigación, basada en una metodología cualitativa, con la utilización de la entrevista en profundidad, como técnica de investigación principal, complementada con una observación participante.

Las entrevistas en profundidad se han realizado a profesionales de distintos ámbitos, dentro y fuera de prisión, con alguna implicación con los procesos de encarcelamiento y excarcelamiento de mujeres extranjeras; $y$, lo más importante, a las internas extranjeras. Destacamos la relevancia de nuestro trabajo de campo, ya que éste ha sido realizado

\footnotetext{
${ }^{4}$ Son centros tipo -o macroprisiones- aquellos construidos tras la reforma de la Ley General Penitenciaria de 1979, al amparo del Plan de Amortización y Creación de Centros Penitenciarios de 1991, con un diseño arquitectónico "modular", cuyo avance más importante es la inclusión de módulos específicos no residenciales, con el fin de implantar las actividades de tratamiento contenidas en dicha ley.

${ }^{5}$ En el momento de escribir estas líneas está siendo realizado el trabajo de campo en la prisión de Alcalá de Guadaira (Sevilla). Éste será completado con los centros de Albolote (Granada), y, fuera de la comunidad autónoma andaluza, los de Topas (Salamanca) y Madrid I, seleccionados por su elevado número de internas extranjeras.
} 
y "grabado"6 en su totalidad dentro de las prisiones, cara a cara con los informantes ${ }^{7}, \mathrm{e}$ incluso, en el caso de las internas extranjeras, en su mismo módulo.

Se han realizado 34 entrevistas a internas extranjeras. Las nacionalidades predominantes son la colombiana y la marroquí. La causa fundamental de ingreso en prisión es el delito "contra la salud pública", más concretamente, el tráfico de drogas, observándose una identificación de las reclusas colombianas con este delito; en el caso de las mujeres marroquíes es también muy común el delito contra la salud pública, aunque varía el tipo de droga con la que se trafica: mientras que las colombianas trafican con cocaína, las marroquíes lo hacen con hachís. Entre estas últimas hemos detectado también otros delitos, como el robo, incendio u homicidio. Las edades de las reclusas entrevistadas oscilan entre los 19 y los 53 años, situándose la media de edad en torno a los 30.

Además, se han realizado 34 entrevistas a profesionales con distintos puestos de trabajo dentro y fuera de las prisiones. Destacamos el alto grado de movilidad de profesionales de prisiones, por lo que su aportación a nuestra investigación ha sido enormemente enriquecedora, dada su experiencia en centros diferentes.

La tarea de explotación y análisis de las entrevistas en profundidad se ha realizado con la ayuda del programa Atlas-ti, versión 2.4, que nos ha facilitado la integración de la información contenida en las entrevistas en una unidad hermenéutica, así como agilizado su organización, explotación y posterior análisis.

\section{Delitos de ACCESO a LA CÁRCEL y NACIONALIDAd}

Según el Informe General 2006 (Dirección General de Instituciones Penitenciarias 2006: 26-27), las mujeres se encuentran en prisión, en aplicación del Código Penal derogado, por los siguientes delitos: delitos contra la salud pública $(28,3 \%)$, robos $(23,3 \%)$ y terrorismo $(20 \%)$. En aplicación de la Ley 10/95 del Código Penal: contra la salud pública $(48,2 \%)$, robos $(24,1 \%)$; es decir, por ambos delitos entran en prisión siete de cada diez internas $(72,3 \%)$.

Al investigar la relación entre tipología delictiva y nacionalidad, nos encontramos con la limitación de que ninguna fuente ofrece datos que vinculen ambas variables, pese a la existencia de algunos estudios sobre la delincuencia en Andalucía (García y Pérez 2006). No obstante, hemos establecido una relación entre nacionalidad y delito, en el caso de las mujeres extranjeras, utilizando los siguientes recursos:

\footnotetext{
${ }^{6}$ Todas las entrevistas han sido recogidas mediante grabadoras y transcritas en su totalidad.

${ }^{7}$ Cuando decimos que "hemos realizado" estas entrevistas, queremos decir que las hemos hecho "personalmente", como recomienda Orti, para orientar el discurso de la entrevista, de forma más o menos directiva, según la finalidad perseguida en cada caso (Orti, A. 1986: 178).
} 
1. Los datos anteriores sobre tipología delictiva de la mujer reclusa en España, que establecen el delito contra la salud pública como causa principal de su ingreso en prisión.

2. Los datos proporcionados por cada centro penitenciario estudiado, de su población reclusa femenina extranjera.

3. La información obtenida en las entrevistas a los profesionales de los centros penitenciarios visitados y del discurso de las propias internas.

4. Por último, los escasos estudios realizados sobre mujeres reclusas extranjeras en Andalucía (Defensor del Pueblo Andaluz 2006) y en España (Miranda 1997; Surt, Sacro, CGIL y Faire 1999; Ribas, Almeda y Bodelón 2002).

Nuestra investigación pone de manifiesto que los perfiles delictivos de las mujeres extranjeras no difieren mucho de los de las mujeres españolas: delitos contra la salud pública y delitos contra la propiedad principalmente, aunque se van definiendo perfiles más novedosos, como es el caso de los delitos de tráfico de personas, explotación sexual, extorsión o estafa, ligados a nacionalidades más recientemente incorporadas a la inmigración y con un peso cada vez mayor en el conjunto de la población inmigrante en España.

El tráfico de drogas va ligado a trayectorias de exclusión social, tanto en el caso de las mujeres españolas como en el de las extranjeras; también la pobreza, la precariedad laboral y el paro e incluso la prostitución están presentes en la mayoría de las historias de vida de las mujeres condenadas por éste u otros delitos, tales como los delitos contra la propiedad, directamente relacionados con el consumo de drogas, siendo éste último un rasgo distintivo de las españolas.

El proceso de criminalización previo al ingreso en prisión de las mujeres está pues relacionado con los contextos sociales y, en el caso concreto de las extranjeras, con los contextos geográficos de origen. En este sentido, podemos apuntar una clara vinculación entre delito y nacionalidad: el tráfico de las "mulas" latinoamericanas, especialmente colombianas, o de las marroquíes, y los nuevos perfiles asociados a la estafa y el tráfico de personas que afecta a las mujeres del Este, principalmente rumanas. No obstante, también cabe señalar que, en las reclusas extranjeras, el delito va ligado a la decisión de emigrar y a la trayectoria migratoria. Tal es el caso de las correos o mulas colombianas, que trafican con drogas como vía para lograr el dinero que les permite afrontar los gastos de la migración. La mayoría de estas mujeres no tienen una trayectoria delictiva previa. Por el contrario, la comisión del delito puede entenderse como puntual para salir de una situación de exclusión, vinculada, en muchos casos, a su condición de inmigrante.

No obstante, en las prisiones andaluzas hemos detectado un importante número de mujeres colombianas y marroquíes que cometieron el delito una vez asentadas en nuestro país. En la mayoría de los casos, a pesar de vivir en España, carecían de permiso de residencia y de trabajo. En el caso de las marroquíes, merecen especial mención aquéllas que residían en las zonas de Ceuta y Melilla, o en zonas marroquíes transfronterizas, con tradición de cultivo y tráfico de hachís; es en este contexto donde se 
enmarca la comisión del delito de un elevado número de mujeres que, en Andalucía, se concentran en la prisión de Algeciras.

"No fue ni coca ni nada [...] un par de kilos de hachís. Estaba desesperada por pagar el alquiler". (Marroquí, 33 años, C. P. Algeciras).

"Yo he limpiado, he trabajado en restaurantes, he cuidado niños, he vendido cosas.... y lo último ya fue entrar en el narcotráfico...lo hice porque me avisaron de Colombia de que me mi hijo necesitaba una operación". (Colombiana, 25 años, C. P. Algeciras).

Entre las internas colombianas — como ya se ha comentado—el perfil dominante es el de la "mula", habitualmente una mujer joven, que inicia el proceso migratorio entrando en España con visado de turista, y que es detenida en el aeropuerto de Barajas, en muchos casos, con pequeñas cantidades de drogas, generalmente cocaína, por las que son castigadas con penas de hasta diez años de prisión, convirtiéndose así en cabezas visibles y víctimas del negocio de los cárteles latinoamericanos, especialmente colombianos.

"Gente, colombianos que llegan a Barajas y lo que conocen es Barajas-Soto del Real...". (Funcionaria de vigilancia, módulo de mujeres).

En general, las mujeres colombianas y marroquíes en prisión por delitos contra la salud pública, se reconocen como parte del negocio de la droga, se sienten explotadas por las mafias y víctimas de un sistema penitenciario, que penaliza en exceso el tráfico de pequeñas cantidades de drogas. El tratamiento que el Código Penal español hace de este delito se entiende en el marco de la consideración de la salud pública como un bien jurídico, así como del diseño de unas políticas contra la droga a nivel internacional. En distintas investigaciones ya se ha recogido el debate sobre la "utilidad" de unas penas que no recaen sobre la parte más importante del negocio, sino sobre los sectores más vulnerables (Miranda y Barberet 1998: 45) (Ribas, Almeda y Bodelón 2005: 34-40).

"Si no hay consumidores, no hay traficantes [...] si hay droga es porque hay peces gordos fuera. No el que, por desgracia, ha cogido 200 ó 300 gramos para buscarse la vida, para meterse en la entrada o el alquiler retrasado. Yo hablo de la gente que cobra cifras redondas ...." (Mujer marroquí, 28 años, preventiva, por delito contra la salud pública. C. P. Algeciras).

En el caso de las mujeres del Este, nuestro estudio pone de manifiesto la existencia de mafias localizadas, tanto en los lugares de origen como en España, dedicadas al tráfico y explotación de personas y a la estafa. Concretamente, con las rumanas, se incorporan estos nuevos perfiles delictivos que, nuevamente, ponen de manifiesto la relación entre delito y nacionalidad. 


\begin{abstract}
"Yo tengo una condena de 20 años ... yo traía mujeres de Rumania, y sí, es verdad, aquí tenían que trabajar para mí en la prostitución; pero ellas sabían a lo que venían ... a cambio, yo les arreglaba papeles ... pero era un trato acordado. Ellas me denunciaron porque así, con la ley, se les concede automáticamente papeles. Yo no estaba sola en esto...lo hacía con mi cuñado, el novio de mi hermana". (Mujer rumana, 22 años. 2. ${ }^{\circ}$ grado. Tráfico y retención ilegal de personas. C. P. de Alhaurín de la Torre).
\end{abstract}

Las mujeres españolas cometen los delitos, en muchos casos, empujadas por sus parejas, quienes las introducen además en el consumo de drogas; es habitual el encubrimiento del varón por parte de estas mujeres, quienes suelen autoinculparse con objeto de salvaguardar el sostenimiento económico familiar que, en el caso de las nacionales, es procurado generalmente por el varón. También es habitual que las internas españolas, especialmente las gitanas, encubran a sus hijos.

"Las gitanas viejas se comen lo de los hijos. Así te lo digo, tienen un sentido del deber, del papel de madre, casi todas las viejas que han estado aquí se han comido lo de los hijos, seguro, seguro; la de los maridos (refiriéndose a la condena) no, porque los maridos estarán comiéndosela por otros lados". (Funcionaria de vigilancia del módulo de mujeres).

Esta circunstancia no se da en el caso de las extranjeras; en su caso la comisión del delito está ligada al fuerte arraigo de mafias internacionales de tráfico de drogas en sus países de origen (como es el caso de Colombia), unido a su condición de ser el sustento de la economía familiar (esto no sucede en la mayoría de los casos de internas españolas), lo que constituye la causa de su decisión de emigrar, como comentamos con anterioridad.

Otra nacionalidad a destacar es la nigeriana, que se duplicó entre 2003 y 2005 (tabla 2), coincidiendo con el desmantelamiento y detención posterior de una extensa banda, asentada en la Costa del Sol, especializada en estafas mediante el procedimiento de las "cartas nigerianas", integrada principalmente por personas de esta nacionalidad.

Asimismo, la nacionalidad brasileña está ligada al delito contra la salud pública y a las redes de prostitución ilegal. Por último, y en lo que respecta a las mujeres chinas, hay que apuntar que, los ciudadanos de esta comunidad que delinquen, cometen un tipo de delito distinto al que es más frecuente en el resto de las nacionalidades, relacionado con la falsificación de distintos productos, o copias ilegales; estos delitos están menos castigados en el actual Código Penal que el delito contra la salud pública, por lo que el número de mujeres chinas en prisión es casi insignificante.

\footnotetext{
${ }^{8}$ Cartas y documentos falsos, que comunicaban una herencia a la persona que los recibía, para cuyo cobro se les exigía el pago de una cantidad de dinero previa.
} 
Un rasgo compartido por las internas extranjeras, que las distingue de las nacionales, es la mayor dificultad de acceso a la libertad provisional antes del juicio. La falta de arraigo que afecta a muchas extranjeras no ofrece suficientes garantías de que estas internas no se evadan de la acción de la justicia. Esta diferencia es percibida negativamente por las internas extranjeras, que manifiestan su descontento ante las prolongadas estancias en prisión, a la espera de juicio. Esta falta de arraigo está relacionada con la inexistencia de un domicilio conocido, o familiares en la misma ciudad, más que con la situación de irregularidad de la reclusa.

"Yo tengo un cliente que está en libertad condicional, a la espera de juicio por delito contra la propiedad intelectual, y está en situación irregular, pero vive con un hijo aquí en Huelva. En cada caso se evalúan muchas circunstancias a la hora de conceder una libertad condicional, como el arraigo, el tipo de delito...". (Abogada experta en extranjería).

Precisamente la ausencia de condena en muchas de las reclusas extranjeras entrevistadas no nos permite confirmar que hayan cometido el delito por el que se encuentran en prisión; sin embargo, sí hemos detectado distintas percepciones y respuestas, ante su relación con éste:

1. En primer lugar, las que reconocen haber cometido el delito del que se les acusa:

"Yo la trafico, yo no la inventé (la droga) [...] hay gente que consume droga y otra que la tiene que vender". (Mujer argentina, 50 años, preventiva, delito contra la salud pública. C. P. Alhaurín de la Torre).

2. En segundo lugar, las que, aun reconociendo la comisión del delito, consideran que éste no reviste gravedad, y que las penas que se le imponen son excesivas:

"Yo no digo que esté bien lo que yo tenía, pero mucho peor es andar poniendo bombas 0 andar matando gente por la calle....una española tiene 1200 euros de fianza y a mí me ponen 35.000 ... a mí me caen desde 9 a 13 años, pero ¿es que estamos todos locos?" (Mujer argentina, 53 años (hermana de la anterior), preventiva, delito contra la salud pública. C. P. Alhaurín de la Torre).

3. Y, por último, las que niegan su relación con el delito:

"Yo estoy aquí por delito contra la salud pública. Trabajaba de limpiadora en una casa, en la casa que cogieron eso ... eso significa que la dueña era traficante, no era yo, pero bueno, [...] las extranjeras somos [...] siempre la culpa para nosotros". (Mujer colombiana, 23 años, delito contra la salud pública. C. P. Alhaurín de la Torre). 
En los tres casos analizados, las reclusas extranjeras no se consideran delincuentes, sino víctimas de una situación límite, que les ha abocado a la comisión del delito.

"Nosotras no descuartizamos, no matamos, no hacemos nada que sea imperdonable". (Mujer argentina, 50 años, preventiva, delito contra la salud pública. C. P. Alhaurín de la Torre).

\section{ACTIVIDADES DE TRATAMIENTO Y RECLUSAS EXTRANJERAS: EL TRABAJO PENITENCIARIO}

Una de las características más relevantes de la moderna prisión española es su finalidad: la reinserción, para lo cual nace el "tratamiento penitenciario" (artículo 59 de la Ley General Penitenciaria, y artículo 25.2 de la Constitución Española de 1978), como conjunto de actividades dirigidas a la consecución de la reeducación y reinserción social. Estas actividades comprenden la clasificación de los internos, educación y enseñanza, formación profesional y ocupacional, actividades socioculturales y deportivas, tratadas en trabajos anteriores (Castillo y Ruiz 2007), y trabajo penitenciario. La Ley Orgánica General Penitenciaria de 26 de septiembre de 1979 no tiene en cuenta la condición de extranjero en materia de régimen y tratamiento penitenciarios, que deben regirse por el principio de Igualdad y No Discriminación según el artículo 3 de dicha Ley y el artículo 118.2 del Reglamento Penitenciario.

El trabajo penitenciario supone un salario y una cotización a la Seguridad Social para los internos, lo que la convierte en la actividad más demandada por mujeres y hombres, extranjeros y nacionales, siendo considerada como un derecho de "aplicación progresiva" (Téllez 1998: 38-39). En la asignación de puestos tienen preferencia los penados sobre los preventivos y los reclusos con cargas familiares sobre aquellos que no las tienen.

En cuanto a los derechos derivados del desempeño de un puesto de trabajo que tienen los extranjeros en España, el Tribunal Superior de Justicia de Madrid, reconoció en el año 2000, la situación legal de desempleo para un extranjero irregular, tras su excarcelación. El 1 de julio de 2005, el Consejo de Ministros adoptó un Acuerdo por el que se aprobaron las Instrucciones en las que se determina el procedimiento para autorizar el desarrollo de actividades laborales, por parte de internos extranjeros, en los talleres productivos de los centros penitenciarios, y el ejercicio de actividades laborales a penados extranjeros en régimen abierto o en libertad condicional. Toda resolución judicial que acuerde el ingreso en prisión de un interno extranjero tiene, así, validez de autorización de trabajo. Igualmente, todo penado extranjero cuya condena no haya sido sustituida por la sanción de expulsión, podrá obtener autorización de trabajo de la Subdelegación del Gobierno, dando validez a la Resolución de la Dirección General de Instituciones Penitenciarias, o del Juez de Vigilancia, acordando el tercer grado o la libertad condicional, siempre que el penado extranjero reúna ciertas condiciones que lo 
permitan, conforme a la vigente normativa de extranjería e inmigración. Estas condiciones son las siguientes:

A. Encontrarse en la situación de residencia o en la de estancia por estudios, en el momento de producirse la condena, teniendo en cuenta la posibilidad que establece el artículo 31.4 de la Ley Orgánica 4/2000.

B. Encontrarse en uno de los supuestos del artículo 45 del Reglamento de la Ley Orgánica 4/2000, aprobado por Real Decreto 2393/2004, para la obtención de una autorización de residencia temporal por circunstancias excepcionales. Éstas son: a) arraigo laboral, 0 arraigo familiar (en los términos que establece el citado artículo 45.2); b) protección internacional (artículo 45.3); c) supuestos por razones humanitarias (artículo 45.4).

C. Encontrarse en uno de los supuestos del artículo 72 del Reglamento de la Ley Orgánica 4/2000, para la obtención de una autorización de residencia permanente.

Asimismo, mediante sentencia del Tribunal Supremo de 9 de junio de 2003, se establece que todo trabajador extranjero sin permiso de residencia ni de trabajo tiene derecho a atención sanitaria y prestaciones económicas por accidente laboral o enfermedad profesional ocurridos en España. Sin embargo, los extranjeros sin permiso de trabajo, una vez cumplida la pena, no tienen derecho a prestación por desempleo.

En esta actividad de tratamiento hemos detectado cierto sesgo de género: en todas las prisiones mixtas se ofertan muchos menos puestos de trabajo para las internas -recordemos que el número de reclusas es muy inferior al de varones- y el tipo de trabajo ofertado está fuertemente marcado por el rol de género. Los puestos de trabajo específicos para los hombres son de carpintería, carpintería metálica, cocina y panadería; mientras que los de las mujeres son de corte y confección, lavandería y limpieza.

"Las mujeres están discriminadas en el tema de la limpieza; [...] a mí eso es una cosa que me da muchísima rabia, que siempre tengan que ser las mujeres las que limpian, pero ¿qué es lo que ocurre? Que como los hombres no limpian bien, pues a la mujer [...] y siempre son las internas mujeres, por el hecho de ser mujer y por el hecho de limpiar bien, por lo que salen, ni más ni menos". (Coordinadora de formación).

Pese a todo, esta actividad es de especial interés para las mujeres extranjeras, puesto que el cobro de un salario les permite mantener el sentido de su proyecto migratorio. Además, gracias a esto, muchas reclusas extranjeras ocultan a sus familiares en sus países de origen que están en prisión, sin olvidar que los sueldos en prisión son más altos que en sus países de origen.

"Mi familia sabe que estoy acá, pero mi hijo menor no sabe que estoy en prisión [...] cree que estoy trabajando". (Mujer, colombiana, 25 años, preventiva; delito contra la salud pública. C. P. de Algeciras). 
Una realidad compartida por reclusas españolas y extranjeras es su rol de madres de familia, que las hace responsables de la organización y funcionamiento de la unidad familiar, de ahí el desorden y la desestructuración que se produce cuando la madre entra en prisión, lo que no sucede si es el padre el que ingresa. Esta repercusión sobre la familia es mucho menor en el caso de las mujeres extranjeras porque - no hay que olvidar - todas ellas han dejado la organización de sus familias ya prevista, con la ayuda de abuelas, tías, hermanas o hijas mayores, antes de emigrar a España. De hecho, según Oso (1998), la inmigración femenina está lejos de articularse como un proyecto individual, de forma que, aunque son las mujeres las protagonistas del fenómeno migratorio, éste responde a un proyecto en muchos casos familiar, a una estrategia organizada con las familias de los países subdesarrollados para supervivencia.

Pese a que uno de los criterios en la asignación de estos puestos de trabajo es - como se ha comentado - priorizar a los penados sobre los preventivos, esto no se cumple en el caso de las reclusas extranjeras, la mayoría de ellas preventivas. Esto se explica por tres razones:

1. El tiempo que están como preventivas en espera de juicio, que es muy prolongado.

2. Una reclusa extranjera necesita el dinero, causa fundamental de su decisión de emigrar a nuestro país;

"En la época en que estuve yo (se está refiriendo a la prisión de Soto del Real), un $90 \%$ de los destinos cobrando estaban copados por los sudamericanos; españoles llegaban muy pocos, era rarísimo, los tenían prácticamente ellos [...] destinos como el de cocina, panadería, que son destinos buenos para ellos porque igual cobras setenta u ochenta mil pesetas, pero para ellos es importantísimo. Y mucha gente de esa, pues oye, mandaban dinero, entonces realmente ellos estaban [...] pues trabajando en España". (Educador, módulo de mujeres).

Por otra parte, esta necesidad de un destino remunerado, garantiza el buen comportamiento de las reclusas.

"Esta mujer ha cambiado desde que está saliendo a limpiar, ha cambiado en sus relaciones, porque aquí se estaba relacionando pues más o menos con las que manejan la droga, y en el momento en el que empezó a salir se le dijo 'hombre, tienes un destino, es bueno, cuídalo porque si no, te vas, [...] a la mínima sales'. Y no es que se haya distanciado, pero mantiene el tipo". (Funcionaria de vigilancia del módulo de mujeres).

"Una sudamericana no te va a dar problemas porque necesita el dinero". (Funcionaria de vigilancia). 
Esta circunstancia ha dado lugar a la construcción de la imagen de la reclusa extranjera como "buena trabajadora-buena interna", puesta también de manifiesto en otras investigaciones (Ribas, Almeda y Bodelón 2005: 105-112).

3. Por último, por su mayor nivel de formación, lo que las capacita para puestos más cualificados dentro de la prisión.

"Una persona en el economato, pues tiene que saber de números, tiene que saber de cuentas, tiene que saber clasificar ... son destinos de confianza, manejan mucho dinero". (Funcionaria de vigilancia).

\section{VIDA EN PRISIÓN A TRAVÉS DE LOS DISCURSOS DE LAS MUJERES EXTRANJERAS}

Las extranjeras, reclusas "primerizas"

Uno de los aspectos que diferencian a las reclusas extranjeras de las nacionales es el carácter no reincidente de las primeras; para todas las reclusas extranjeras entrevistadas se trataba de su primer ingreso en un centro penitenciario, mientras que, en el caso de las nacionales, es habitual que entren y salgan de prisión, existiendo un alto porcentaje de reincidencia, especialmente entre las mujeres consumidoras de drogas. Esta circunstancia, unida a otras derivadas de su condición de extranjeras - por ejemplo, el desconocimiento del idioma, del sistema policial, judicial y penitenciario español; la desinformación sobre las posibilidades de asistencia 0 ayuda por parte de las distintas instituciones, ya sean oficiales o de carácter asociativo-, provoca en las extranjeras que entran por primera vez en prisión una situación de desorientación y desconcierto que agrava su situación como reclusas. A las reclusas españolas, a pesar de presentar un nivel de formación mucho más bajo que las extranjeras, sus entradas y salidas de la cárcel les ha propiciado un cierto conocimiento de nuestro sistema judicial y penal, además de estar más familiarizadas con el funcionamiento de la prisión.

Con respecto al hándicap que supone el desconocimiento del español, éste se solventa en el momento de su detención ya que, en las instancias policiales, se les facilita un intérprete que les asiste en su declaración y comunicación con sus abogados, habitualmente asignados de oficio. En el momento de su entrada en prisión, el centro penitenciario facilita a la interna extranjera un folleto informativo editado en su idioma, en el que se incluyen las normas de régimen interno del centro; a este respecto, la administración penitenciaria tiene la obligación de editar este folleto en los idiomas de los grupos más representados en cada centro penitenciario. Igualmente, tiene el deber de informar a la reclusa extranjera sobre las distintas formas de excarcelación y expulsión previstas en la ley. No obstante, esta información no es suficiente; debería ir acompañada de una asistencia personalizada a la reclusa extranjera que, en la mayoría de los casos, no se produce, incluso transcurridas varias semanas tras su ingreso en prisión. Este hecho ha sido constatado en los centros penitenciarios en los que se ha realizado el trabajo de campo, siendo una de las quejas más habituales de las reclusas extranjeras: 
"Para las chicas que no hablan español es muy difícil comunicar, para preguntar cosas, instancias [...] los problemas de justicia, abogados...no conozco cómo hacer". (Mujer marroquí, 28 años, preventiva; delito contra la salud pública. C. P. Algeciras).

"Lo pasé muy mal, primero porque no hablaba la lengua, después porque me encontré con personas extrañas que nunca pensé encontrarme en mi vida...". (Mujer angoleña, 28 años, preventiva, delito contra la salud pública. C. P. de Huelva).

\section{Movilidad penitenciaria y percepción de las prisiones españolas}

Otra de las peculiaridades que presentan las internas extranjeras tiene que ver con la movilidad penitenciaria. En algunos de los escasos trabajos publicados en España sobre extranjeros en prisión se habla de "dirigismo institucional" hacia unos centros penitenciarios determinados (Ribas, Almeda y Bodelón 2002: 112), en los que se concentran las mujeres extranjeras, apuntando a la existencia de una discriminación de género. En nuestra investigación hemos encontrado que este "dirigismo institucional" efectivamente existe, pero afecta tanto a mujeres como a hombres extranjeros, por lo que rebatimos, en este aspecto la existencia de una discriminación de género; se trata más bien de una discriminación en función de la nacionalidad, no del género, sustentada en primer lugar, en el criterio del "arraigo", que se tiene en cuenta para todos los presos, nacionales y extranjeros; este criterio -ya comentado con anterioridad - trata de garantizar el derecho de todo interno a cumplir su condena en su lugar de origen y en el que tiene un arraigo familiar. En segundo lugar, el hecho de que la mayor parte de la población reclusa extranjera se concentre en prisiones como Topas, Brievas, Alicante o Málaga, se debe -especialmente en aquellos casos en los que las prisiones están situadas en localidades con una baja tasa de criminalidad - a una política de rentabilización de las plazas penitenciarias. Esto hay que matizarlo con el hecho de que muchos presos extranjeros manifiestan una preferencia por establecimientos situados en grandes ciudades, en las que existe una mayor presencia migratoria, y disponen de una red familiar y/o de personas de su misma nacionalidad, tanto dentro como fuera del centro penitenciario. Encontramos, además, otros centros penitenciarios con un elevado porcentaje de población reclusa extranjera debido a su proximidad a los puntos de entrada de extranjeros a España, donde son detenidos. Son los casos de la prisión de Soto del Real (Madrid), por su proximidad al aeropuerto de Barajas, y de la prisión de Algeciras (Cádiz), cercana al puerto de Algeciras.

Además de este supuesto, en nuestra investigación hemos detectado casos de presas extranjeras que han sido conducidas a otras prisiones, siguiendo el criterio de arraigo, a petición propia. 
"Me han llevado, la primera vez, a una prisión de Girona; después Zaragoza, después Madrid, después Córdoba [...] Aquí estoy sola, hasta ahora no ha venido nadie, como es muy lejos [...] yo quiero pedir ahora a Madrid, porque allí está mi marido". (Mujer rumana, 24 años, preventiva; presunto delito de hurto. C. P. Huelva).

La movilidad penitenciaria, tanto la vivida en primera persona como la experimentada por otras reclusas extranjeras, proporciona a este colectivo diferentes percepciones sobre los distintos centros penitenciarios españoles.

La visión que las mujeres extranjeras tienen de las prisiones españolas, tiene mucho que ver con los centros penitenciarios en los que han cumplido condena, ya que cada uno de ellos está muy marcado por distintas circunstancias: si es o no prisión tipo o, si es una prisión de mujeres; si tiene o no unidad de madres; el estilo de la dirección del centro; el número de preventivas; el trato y la relación con las funcionarias; la mayor 0 menor presencia de extranjeras; la oferta de actividades formativas y ocupacionales; la posibilidad de acceso a puestos remunerados; la asistencia médica; la existencia de tejido asociativo de apoyo; las líneas de actuación de la junta de tratamiento del centro y del juez de vigilancia penitenciaria correspondiente; incluso la comida.

"Mejor ésta que aquélla (se refiere a la antigua prisión madrileña de Yeserías, actualmente, Centro de Inserción), porque aquélla era de película. Allí había de todo, navajas, jeringuillas [...] eso era una mafia, te mataban [...] había negras, gitanas, sudamericanas, aquí no se ve eso, y entraba mucha droga, mucha. Cuando era día de cobro te estaban esperando tres o cuatro para quitarte el dinero, en fin". (Mujer marroquí con nacionalidad española, $2{ }^{\circ}$ grado; delitos de hurto, contra la salud pública y homicidio. C. P. Huelva)

"Yo estuve en Albolote. Allí las funcionarias son un amor, superbuena gente, colaboran, te hacen un favor, son amables; a la hora del recuento tú no tienes que pararte como si ellas fueran unas reinas, simplemente, con que te vean que estás en la celda basta. Allí se ponen a charlar con una, le llevan revistas; o sea, el trato es diferente totalmente". (Mujer colombiana, 24 años; preventiva; delito contra la salud pública. C. P. Alhaurín de la Torre).

Las imágenes que tienen de otras prisiones, bien por rumores o por experiencias de otras reclusas extranjeras, dirigen sus demandas con respecto a sus traslados:

"Yo he escuchado bien de Alcalá. Espero no llego a estar allí, pero si me condenan, lo voy a pedir". (Mujer búlgara, 25 años, preventiva; delito contra la salud pública. C. P. Alhaurín de la Torre).

"Yo no pedí Huelva, aunque allí estaban mis padres, yo pedí Alcalá de Guadaira, porque de allí se sale más rápido". (Mujer marroquí, 21 años, preventiva; delito contra la salud pública. C. P. Algeciras). 
La oferta de puestos de trabajo remunerados y de actividades socioculturales es uno de los aspectos más determinantes en relación a los niveles de satisfacción expresados por las internas extranjeras:

"Aquí no hay trabajo, no hay talleres, no hay nada; hay dos talleres, y este año se cierra uno que es el de cerámica, que nosotros vamos. Si hubiera trabajo, ordenadores, talleres, y eso [...] porque estar en el patio tantas horas trae problemas". (Mujer argentina, 50 años; delito contra la salud pública. C. P. de Alhaurín de la Torre).

En cualquier caso, al margen de las diferentes percepciones que tienen las extranjeras de cada uno de los centros, es unánime la visión positiva que todas ofrecen de la prisión española, en comparación con la de sus países de origen.

"Cuando me trajeron aquí, me llevaron al módulo de ingresos, y yo preguntaba que cuándo me iban a llevar a la prisión y me respondían ya estás en la prisión, y yo no me lo creía. Todo el mundo vestía normal y en mí país llevan camisetas de rayas [...] Todo está limpio y bonito". (Mujer rumana, 27 años, preventiva; hurto, C. P. Huelva).

\section{Comunicaciones y visitas}

El interno tiene derecho a comunicarse, de "forma personal" (cara a cara), a través de tres tipos de comunicaciones (Artículo 45 del Reglamento Penitenciario):

1. Las comunicaciones íntimas o vis a vis. El interno tiene derecho, como mínimo, a una comunicación íntima al mes, con una duración de entre una y tres horas, con su cónyuge o persona con la que acredite tener una relación de pareja, aceptándose, en igualdad de condiciones, la relación de parejas del mismo sexo. La exigencia de acreditar la existencia de una relación de afectividad sólida, en el caso de no ser matrimonio, viene impuesta como medida para evitar el ejercicio de una prostitución encubierta en el mismo centro penitenciario. Esta relación debe tener una estabilidad mínima de seis meses. En el caso de que ambos comunicantes se encuentren en prisión, los Juzgados de Vigilancia Penitenciaria vienen aceptando la relación epistolar previa entre dos reclusos, como acreditación.

"Yo no sé cómo está mi marido, yo ha hecho instancia y como no tengo papel de vivencia me lo denegaron. Vivimos juntos como pareja pero no estamos casados. Me han pedido el libro familiar, pero no me dan vis a vis como los matrimonios". (Mujer marroquí, 28 años, con su pareja en la misma prisión; preventiva; delito contra la salud pública. C. P. Algeciras).

2. Las comunicaciones "familiares": que podrán ser con amigos y "allegados", también una vez al mes como mínimo, y con una duración de un máximo de tres horas. El problema se presenta a la hora de interpretar el término "allegados", contenido en el citado artículo. 
"En realidad, se puede decir que el término "allegados" no tiene un significado concreto en el ámbito penitenciario, por lo que el artículo 45 se interpreta en el sentido estricto, de que sólo los familiares del interno tienen derecho a comunicar personalmente con él. Se ha establecido como norma que, si se demuestra que ha existido una comunicación oral, en los locutorios, de forma continuada, en este caso se eleva al juez de vigilancia penitenciaria la solicitud del interno de poder comunicar personalmente con esa persona, pese a no ser familiar; entonces el juez dicta un auto autorizándolo. Sí, esto se aplica para todos los internos, nacionales y extranjeros". (Subdirector de seguridad).

3. Las comunicaciones de "convivencia". Estas comunicaciones podrán tener lugar con cónyuge —o con una persona ligada por una relación semejante de afectividad—e hijos que no superen los diez años de edad; estas comunicaciones son compatibles con las anteriores y tienen una duración máxima de seis horas. No se establece un número mínimo ni máximo de estas visitas.

Además de estas comunicaciones, el interno tiene derecho a comunicar oralmente, a través de los locutorios, con familiares y amigos (en este caso, sí queda establecido con claridad que cualquier persona puede tener este tipo de comunicación con el interno), como mínimo, dos veces a la semana y con una duración mínima de veinte minutos, pudiendo acumular en una sola visita semanal el tiempo que hubiera correspondido normalmente a dos visitas.

Los internos también tienen derecho a comunicaciones escritas (Artículo 46, Reglamento Penitenciario), sin limitaciones en cuanto al número de cartas o telegramas que puedan mandar o recibir, y a comunicaciones telefónicas (Artículo 47, Reglamento Penitenciario); éstas podrán autorizarse cuando los familiares residan en localidades alejadas, o no puedan desplazarse para visitar al interno. Tendrán una frecuencia máxima de cinco llamadas por semana (recientemente aumentadas a ocho), y con una duración máxima de cinco minutos; se realizarán en presencia de un funcionario y su importe será satisfecho por el interno, salvo cuando se trate de comunicar a sus familiares o abogado su ingreso en prisión o su traslado a otro centro penitenciario en el momento del ingreso (Artículo 41.3, Reglamento Penitenciario).

"Aquí hay una cosa muy mala que en esta cárcel no funciona. Hace dos semanas que no tengo carta de mi marido, porque en el comedor, las otras hablan mucho, y por eso las señoritas no han dado la carta, pero yo no tengo la culpa de que las otras hablan y es una carta muy importante porque no puedo hablar por el teléfono y tengo que saber por escrito". (Mujer nigeriana, 30 años, preventiva; delito de estafa. C. P. Algeciras).

Un aspecto importante, que afecta de manera especial a las reclusas extranjeras, es la escasa duración de las llamadas telefónicas; debemos tener en cuenta que, en muchos casos, las familias de estas internas carecen de teléfono en sus hogares, por lo que tienen que llamar a casas de familiares o amigos. Esto, unido a que, en muchas ocasiones, las llamadas internacionales tardan en conectar, hacen insuficientes los cinco minu- 
tos para que la interna pueda tener una conversación. Esta circunstancia es reconocida incluso por las propias funcionarias:

"Simplemente llamar por teléfono para ellas supone [...] cinco minutos, que es lo que se les permite la llamada de teléfono, para una persona que está llamando a Colombia o está llamando a Rumania no es nada de tiempo; en cambio, para aquí, cinco minutos sí es tiempo". (Funcionaria de vigilancia).

Además, no se tiene en cuenta la diferencia horaria con respecto a sus países de origen para realizar las llamadas telefónicas, de forma que sea factible la comunicación; el Reglamento sólo establece a este respecto que el Director será el que autorice la comunicación y señalará la hora en que deba celebrarse. En este sentido, en la mayoría de los centros penitenciarios, el horario que se establece para todas las llamadas es de 9.30 a 13.30 y de 16.30 a 19.30, coincidiendo con el horario durante el cual los reclusos tienen que permanecer fuera de sus celdas. Es una queja frecuente entre las internas extranjeras, el hecho de que no se tenga en cuenta la diferencia horaria con sus países:

"Resulta que hace quince días que se me murió mi papá, resulta que yo tenía solamente dos llamadas, y me comuniqué con mi hermana, [...] y, pues, cuando me dio la noticia de que había muerto mi papá, yo colgué inmediatamente y me puse toda desesperada. Después yo volví a llamar a mi hermana para preguntar cómo había sido todo [...] pues, ya se me acabaron las llamadas. Así que le pedí a la funcionaria que, por favor, me sacara a hacer una llamada, que yo quería saber cómo estaba mi madre. Y me dijeron que no. Al otro día, una de las funcionarias se burló de mí y me dijo 'ija! Tú eres la que querías una llamada a las doce de la noche'. (Mujer colombiana, 24 años, preventiva; delito contra la salud pública. C. P. Alhaurín de la Torre).

En lo que respecta a reclusos extranjeros y comunicaciones, el Reglamento sólo hace una breve alusión, estableciendo que las comunicaciones y visitas se organizarán de forma que satisfagan las necesidades especiales de estos reclusos, a los que se aplicarán, en igualdad de condiciones con los nacionales, las reglas generales establecidas al respecto (Artículo 41.7, Reglamento Penitenciario). Y, con carácter general —para todos los internos- que la organización de las visitas se hará teniendo en cuenta las dificultades de los desplazamientos de los familiares (Artículo 42, Reglamento Penitenciario).

"No ha venido a verme nadie porque esto es muy lejos". (Mujer rumana, 24 años, preventiva; delito de hurto. C. P. Huelva).

En definitiva, observamos que se da una aplicación estricta de la normativa respecto de las comunicaciones a las que tienen derecho los internos, lo que se traduce en una situación de desventaja de las reclusas extranjeras, a la hora de poder ejercer sus derechos a 
comunicarse. En la práctica, esta situación es -en ocasiones— paliada por las propias funcionarias, con el riesgo de generar quejas por parte de las internas nacionales:

"Aquí el problema de las gitanas [...] que si llaman más las colombianas, que si tienen favoritismo [...] porque a lo mejor les das un poco de margen a la hora de llamar. Ten en cuenta que las colombianas tienen que llamar a deshoras como quien dice, por el cambio horario". (Funcionaria de vigilancia).

\section{Extranjeras y relaciones con otras presas}

En las prisiones investigadas no hemos detectado actitudes ni comportamientos racistas entre las reclusas de distintas nacionalidades. En este aspecto, parece que la institucionalización hace prevalecer el estatus de presa sobre el derivado de la nacionalidad. Las extranjeras, en general, no perciben conductas ni actitudes racistas por parte de las internas españolas:

"Aquí me recibieron bien [...] los primeros días preguntando si yo quiero un café, un leche, que yo no lloro, que agora que estoy aquí tienes que ser fuerte, si quieres un cigarro, y todo; me trataron bien" "No, no, no [...] gracias a Dios hasta agora no, no he tenido ninguna molestia contra eso (refiriéndose a la posibilidad de discriminación por el color negro de su piel)". (Mujer angoleña, residente en Portugal; 28 años, preventiva; delito contra la salud pública; C. P. de Huelva).

"Hay más racismo en la calle que aquí dentro [...] yo esas dificultades ya las he pasado fuera, te ven en la calles y como eres marroquí ya eres prostituta". (Mujer marroquí; 33 años; segundo grado; delito contra la salud pública; C. P. Algeciras.)

No obstante, sí hemos percibido una clara tendencia a la formación de guetos por las distintas nacionalidades. Estos guetos son percibidos e identificados por el resto de las reclusas y las funcionarias. Así, las internas sudamericanas son identificadas como colombianas por las presas españolas e incluso, en algunos casos por las propias funcionarias, independientemente del país latinoamericano de procedencia. De la misma manera, el calificativo de "moras", es utilizado por las internas españolas para referirse a todas las mujeres árabes, incluso a las mujeres españolas procedentes de Ceuta y Melilla.

"Las africanas daban la cara por mí, me identifican a mí con ser árabe, africana. Sí claro, es que los rasgos lo dicen, lo que pasa es que ellos no comprenden que yo no sé ni leer ni escribir en marroquí, como me crié en Ceuta y fui al colegio español y todo, entonces no sé, me considero más española que marroquina ¿no? [...] por eso les digo que yo he ido a Marruecos pero de vacaciones [...] incluso, al principio se creían que yo no tenía papeles españoles. Yo soy musulmana, pero yo no la practico". (Mujer 
marroquí con nacionalidad española; 46 años, segundo grado; delitos contra la salud pública, hurto y homicidio. C. P. Huelva).

Las extranjeras, por su parte, adjudican ciertos estereotipos a las internas españolas: "yonquis", "consumidoras" "drogatas", que tienen una educación inferior, etc:

"[...] las otras (refiriéndose a las españolas) no tienen tanta educación para pedir un favor...." (Mujer argentina, 50 años; preventiva; delito contra la salud pública).

Pese a todo, encontramos también internas que afirman no sentirse discriminadas en la prisión, ni por parte de sus compañeras reclusas ni de las funcionarias:

"Yo no he sentido racismo en esta prisión ni en Puerto Il, que es donde yo entré, ni por parte de mis compañeras ni de las funcionaria; al contrario, me tratan con cariño y respeto". (Mujer colombiana, 25 años, preventiva; delito contra la salud pública. C. P. Algeciras).

Si bien no se perciben actitudes y conductas racistas entre las internas, la observación participante llevada a cabo, así como las entrevistas realizadas, ponen de manifiesto la existencia de problemas de convivencia entre reclusas, extranjeras y nacionales. La causa principal que subyace tras esta situación es la diferencia educacional entre unas y otras: las extranjeras presentan un nivel cultural y de habilidades sociales muy superior, que se refleja en su comportamiento y en su trato con los profesionales de la prisión y con el resto de sus compañeras reclusas, incluso en sus demandas a la dirección del centro penitenciario; mientras que las internas españolas presentan elevados niveles de analfabetismo y carencias, en lo que respecta a valores y normas esenciales de convivencia:

"Nosotras lo que venimos pidiendo es que nos den un módulo de respeto. Nosotras tratamos con educación a las funcionarias. Estamos cumpliendo nuestra pena, sí, pero no tenemos por qué aguantar todo el día los gritos y las peleas de las españolas, que esté todo sucio y se tiren las cosas al suelo. Ellos (las funcionarias y la dirección) saben que nosotras no somos así...)". (Colombiana, 39 años, preventiva, delito contra la salud pública. C. P. de Córdoba).

"Las extranjeras son otra cosa. Son mucho más correctas en el trato, más educadas, saben lo que piden, siguen las normas. Han hecho incluso una instancia pidiendo un módulo de respeto. Y llevan toda la razón, pero no podemos dárselo porque no hay medios". (Educadora módulo de mujeres).

Los problemas de convivencia se encuentran claramente agravados por el hecho de que en las prisiones mixtas las mujeres, a diferencia de los varones, conviven en un único módulo, independientemente de: 
1. su grado de clasificación y,

2. del tipo de interna de que se trate (personalidad y carácter, participación en programas específicos, etc.).

\section{CONCLUSIONES Y PROPUESTAS DE ACTUACIÓN}

El cambio más importante que ha experimentado la institución penitenciaria española en los últimos diez años ha sido el incremento de internos extranjeros, de forma que, en la actualidad, suponen casi el $40 \%$ del total de la población reclusa. Es especialmente significativo el crecimiento de las mujeres extranjeras en prisión, que han llegado a triplicarse, convirtiendo a España en el país europeo con mayor número de mujeres en prisión. Este proceso ha supuesto la incorporación de nuevas y diversas nacionalidades a la población penitenciaria general y a la femenina en particular. Estos cambios hacen necesarias investigaciones que introduzcan las perspectivas de extranjería y de género en los estudios sobre el ámbito penitenciario, casi inexistentes en nuestro país; sólo a través de estas perspectivas se pueden poner de manifiesto la realidad actual de nuestras prisiones y las especificidades que presentan las reclusas extranjeras. Su desconocimiento dificulta el funcionamiento de las prisiones y el trabajo de sus profesionales. Con nuestro trabajo pretendemos contribuir a paliar estas carencias, y a facilitar la adaptación de las actividades tratamentales y educativas penitenciarias a las peculiaridades que caracterizan a las internas extranjeras. A continuación, exponemos las conclusiones principales de nuestro trabajo:

I. A medio plazo, si el incremento comentado continúa, las mujeres extranjeras constituirán la mayoría de las mujeres presas en España.

II. Hasta el año 2005, en las prisiones españolas el grupo con mayor presencia de mujeres extranjeras lo constituía el de las internas latinoamericanas (especialmente colombianas), seguido de las mujeres marroquíes. El resultado del trabajo de campo realizado apunta una tendencia hacia el incremento de reclusas de los países de Europa del Este, principalmente de nacionalidad rumana, así como a una diversificación de las nacionalidades.

III. En cuanto a los perfiles delictivos, las mujeres reclusas tanto nacionales como extranjeras, a diferencia de los reclusos varones, no suelen cometer delitos violentos. La causa de ingreso en prisión más común es el delito contra la salud pública.

IV. Hemos detectado una relación entre delito y nacionalidad que se manifiesta, fundamentalmente, en la relación entre el delito contra la salud pública y las nacionalidades latinoamericanas, especialmente la colombiana y, otros delitos como la estafa y explotación de personas, con la nacionalidad rumana. 
V. Las presas extranjeras no se consideran a sí mismas como criminales. Defienden la comisión del delito como algo ocasional, y lo justifican como un comportamiento derivado de su situación de exclusión social.

VI. Los perfiles de las internas españolas y extranjeras son diferentes. Las extranjeras tiene un nivel educacional y de habilidades sociales mayor; además, presentan un mejor estado físico y psicológico y no consumen drogas, mientras que el consumo de drogas es un rasgo que define a las internas españolas.

VII. Las internas extranjeras declaran que, en contraste con lo que perciben fuera del centro penitenciario, no hay racismo dentro de la prisión, ni entre las presas, ni en sus relaciones con los profesionales.

VIII. Las mujeres extranjeras permanecen más tiempo en prisión que las nacionales, principalmente por dos causas: las extranjeras sufren en mayor medida la prisión preventiva, como garantía ante el riesgo de fuga; además, tienen más dificultades para conseguir la libertad condicional como consecuencia, en muchos casos, de la ausencia de redes familiares de apoyo 0 un contrato de trabajo.

IX. Las reclusas extranjeras manifiestan una percepción positiva de las prisiones españolas, que contrasta con la opinión, mucho más negativa de las españolas. Sin embargo, las extranjeras se quejan de aspectos como la comida, el cuidado de la salud y la escasez de actividades dirigidas específicamente a las mujeres.

X. Una de las principales razones que sustentan la percepción positiva de las extranjeras de la institución penitenciaria es el hecho de que en prisión pueden desempeñar un trabajo y recibir un salario, lo que les permite continuar su proyecto migratorio, enviando dinero a su país de origen.

La elevada presencia de mujeres extranjeras en las prisiones españolas, así como su tendencia de crecimiento y sus características - que las define como un grupo diferenciado con respecto a las reclusas nacionales- están produciendo importantes impactos en el sistema penitenciario español que, previsiblemente, irán en aumento. Estos impactos se ven acrecentados por la diversidad de nacionalidades, presentes entre las internas extranjeras, y se concretan en distintos aspectos: organización de los espacios físicos, recursos humanos y económicos, actividades de tratamiento y de ocio; cuidado de la salud y atención sanitaria, redes de apoyo y organizaciones no gubernamentales, comunicaciones, y gestión del funcionamiento cotidiano de la prisión en general. En definitiva, estas transformaciones exigen la adaptación del sistema penitenciario español y sus prisiones a esta nueva realidad.

A modo de conclusión, algunas propuestas de actuación:

- Adaptar los datos estadísticos penitenciarios, de forma que reflejen las características de la actual población penitenciaria española, y que permitan relacionar las variables género, nacionalidad y delito; así se facilitaría la construcción de un perfil sociodelictivo de las reclusas y la diferenciación entre nacionalidades. 
La ausencia de este tipo de datos supone un obstáculo para la investigación.

- Diseñar un protocolo de información y orientación, destinado específicamente a las reclusas extranjeras, más allá del folleto informativo que se les facilita en su idioma, claramente insuficiente.

- Ampliar y adaptar la oferta formativa y educacional a los intereses y necesidades de estas internas, quienes no están interesadas en la formación reglada, y sí en el aprendizaje de un oficio. Esta oferta no debe ser discriminatoria con respecto a la de los varones.

- Aumentar los puestos de trabajo remunerados para todas las internas, evitando el sesgo de género que existe actualmente.

- Regular, flexibilizando el sistema de comunicaciones, principalmente telefónicas, adaptándolas al cambio horario y a las circunstancias sociofamiliares, que afectan a las reclusas extranjeras.

- Atender las exigencias impuestas por la clasificación de las internas, dotando de diferentes espacios de convivencia, en función de la tipología de internas.

\section{REFERENCIAS BibLIOGRÁFICAS}

Castillo, J. y M. Ruiz. 2007. "Un reto educativo en el siglo XXI: la educación de delincuentes dentro del ámbito penitenciario. Una perspectiva de género" Revista de Educación 9: 301-315.

Quintero, G. Morales, F. Prats, J.M. Tamarit, J.M., y García, R. 1999. Código Penal. Pamplona: Aranzadi.

Constitución Española. Texto íntegro. 1993. Biblioteca de legislación. Serie menor. Madrid: Civitas.

Defensor del Pueblo Andaluz. 2006. Mujeres privadas de libertad en centros penitenciarios de Andalucía, Informe Especial al Parlamento Andaluz. Sevilla: Junta de Andalucía.

Díez, J. L. 2006. "Algunos rasgos de la delincuencia en España a comienzos del siglo XXI" Revista Española de investigación criminológica 4: 1-19. Consultado el 21 de mayo de 2009. www.criminologia.net.

Dirección General de Instituciones Penitenciarias. 2004. Informe General 2003. Madrid: Ministerio del Interior.

Dirección General de Instituciones Penitenciarias. 2005. Informe General 2004. Madrid: Ministerio del Interior.

Dirección General de Instituciones Penitenciarias. 2006. Informe General 2005. Madrid: Ministerio del Interior.

Dirección General de Instituciones Penitenciarias. 2008. Informe General 2006. Madrid: Ministerio del Interior. 
España. 2005. "Real Decreto 2393/2004, de 30 de diciembre, por el que se aprueba el Reglamento de la Ley Orgánica 4/2000, de 11 de enero, sobre derechos y libertades de los extranjeros en España y su integración social." Boletín Oficial del Estado 006:485-539, 7 de enero del 2005.

España. 2001."Real Decreto 864/2001, de 20 de julio, por el que se aprueba el Reglamento de ejecución de la Ley Orgánica 4/2000, de 11 de enero, sobre derechos y libertades de los extranjeros en España y su integración social reformada por Ley Orgánica 8/2000." Boletín Oficial del Estado 174:26552-26603, 21 de julio del 2001

España .1996. "Real Decreto 190/1996, de 9 de febrero por el que se aprueba el Reglamento Penitenciario." Boletín Oficial del Estado 40: 5380-5435,15 de Febrero 1996

García, E. 2001. Inmigración y delincuencia en España: análisis criminológico. Valencia: Tirant lo blanch.

García, E y F. Pérez. 2006. Análisis de la delincuencia en Andalucía. Sevilla: Centro de Estudios Andaluces, Consejería de la Presidencia. Junta de Andalucía.

García, M. 1979. Sobre el método. Problemas de investigación empírica en Sociología. Madrid: CIS.

Garrido , L. 1989. "Los permisos penitenciarios." Revista de Estudios Penitenciarios 1: 85-97.

Gibbons, A. 1998. "Ladies' Lace-Making and Imprisonment." Visual Sociology 13: 91-103.

Goffman, E. 1968. Asylums. Harmondsworth: Penguin.

Halford, S. and C. Knowles. 2005. "More than Words: Some Reflections on Working Visually." Sociological Research Online 10. Consultado el 12 de octubre del 2008. (http://www.socresonline.org. uk/10/1/knowleshalford.html)

Instituto Nacional de Estadística. 2006. Anuario Estadístico de España 2006. Madrid: Instituto Nacional de Estadística.

Dirección General de Instituciones Penitenciarias. 2001. I 14/2001 TGP. Madrid: Ministerio de Interior.

Dirección General de Instituciones Penitenciarias. 2005. I 18/2005 TGP. Madrid: Ministerio del Interior.

España. 2000."Ley Orgánica 4/2000, de 11 de enero, sobre derechos y libertades de los extranjeros en España y su integración social." Boletín Oficial del Estado 010:1139-1150, 12 de enero del 2000.

Ministerio del Interior (España) - Instituciones Penitenciarias: Consultado el 20 de octubre de 2008. (http://www.mir.es/INSTPEN/)

Miranda, M. J. 1997. "Mujeres en prisión." Revista 8 de marzo 27: $19-21$.

Miranda, M. J. y R. Barberet. 1998. Análisis de la eficacia y adecuación de la política penitenciaria a las necesidades y demandas de las mujeres presas. Barcelona: Mimeo.

Ortí, A. 1986. "La apertura y el enfoque cualitativo o estructural: la entrevista abierta y la discusión en grupo." Pp. 178-193 en El análisis de la realidad social. Métodos y Técnicas de Investigación 
Social, compilado por García, Alvira e Ibáñez. Madrid: Alianza.

Oso, L. 1998. La inmigración hacia España de mujeres jefas de hogar. Madrid: Ministerio de Trabajo y Asuntos Sociales, Instituto de la Mujer.

Ribas, N., I. Almeda y E. Bodelón. 2005. Rastreando lo invisible. Mujeres extranjeras en las cárceles. Barcelona: Anthropos.

Ribas, N., E. Almeda y E. Bodelón. 2002. "La criminalización femenina de la inmigración: resultados de una investigación." Pp. 45-78, en La inmigración en España: contextos y alternativas, vol. II, Actas del III Congreso sobre la Inmigración en España (Ponencias), editado por García, F. J. y C. Muriel. Granada: Laboratorio de Estudios Interculturales.

Surt, Sacro, CGIL. 1999. De la prisión a la inserción. Intercambio de experiencias de inserción sociolaboral de las personas (ex) presas. Barcelona: Dirección General V (Ocupación, Relaciones Laborales y Asuntos Sociales ).

Tellez, A. 1998. Seguridad y disciplina penitenciaria. Madrid: Edisofler.

JOAQUINA CASTILLO ALGARRA es Doctora en Sociología por la Universidad Pontificia de Salamanca en Madrid; primer premio a la mejor tesis doctoral del Instituto Andaluz del Deporte (2006). Profesora de la Universidad de Huelva en la Facultad de Ciencias de la Educación. Ha participado en múltiples proyectos de investigación y publicaciones sobre el ámbito penitenciario, como la monografía Deporte y reinserción penitenciaria (Consejo Superior de Deportes, 2005).

MARTA RUIZ GARCÍA es Catedrática de Escuela Universitaria del Departamento de Sociología y Trabajo Social desde el año 2000 y Miembro del Seminario de Estudios de la Mujer de la Universidad de Huelva. Ha trabajado en diversos proyectos de investigación y publicado distintos capítulos en monografías sobre migraciones así como artículos en revistas nacionales e internacionales en materia de género e inmigración y sociología de las prisiones.

RECIBIDO: $15 / 05 / 2008$

ACEPTADO: 02/02/2009

Publicado on-line: 26 de abril de 2010 